\title{
Innovation Diffusion and Mobile Payment Adoption amongst Postgraduate Students of UiTM Shah Alam
}

Mohd Safwan Ramli, Hazlin Hasan, Zuria Akmal Saad, Muhammed Soffiq Saripin and Asmahan Zakaria

To Link this Article: http://dx.doi.org/10.6007/IJARBSS/v12-i1/12082 DOI:10.6007/IJARBSS/v12-i1/12082

Received: 05 November 2021, Revised: 07 December 2021, Accepted: 30 December 2021

Published Online: 18 January 2022

In-Text Citation: (Ramli et al., 2022)

To Cite this Article: Ramli, M. S., Hasan, H., Saad, Z. A., Saripin, M. S., \& Zakaria, A. (2022). Innovation Diffusion and Mobile Payment Adoption amongst Postgraduate Students of UiTM Shah Alam. International Journal of Academic Research in Business and Social Sciences, 12(1), 1911-1923.

Copyright: (c) 2022 The Author(s)

Published by Human Resource Management Academic Research Society (www.hrmars.com) This article is published under the Creative Commons Attribution (CC BY 4.0) license. Anyone may reproduce, distribute, translate and create derivative works of this article (for both commercial and non0-commercial purposes), subject to full attribution to the original publication and authors. The full terms of this license may be seen at: http://creativecommons.org/licences/by/4.0/legalcode

Vol. 12, No. 1, 2022, Pg. 1911- 1923

Full Terms \& Conditions of access and use can be found at http://hrmars.com/index.php/pages/detail/publication-ethics 


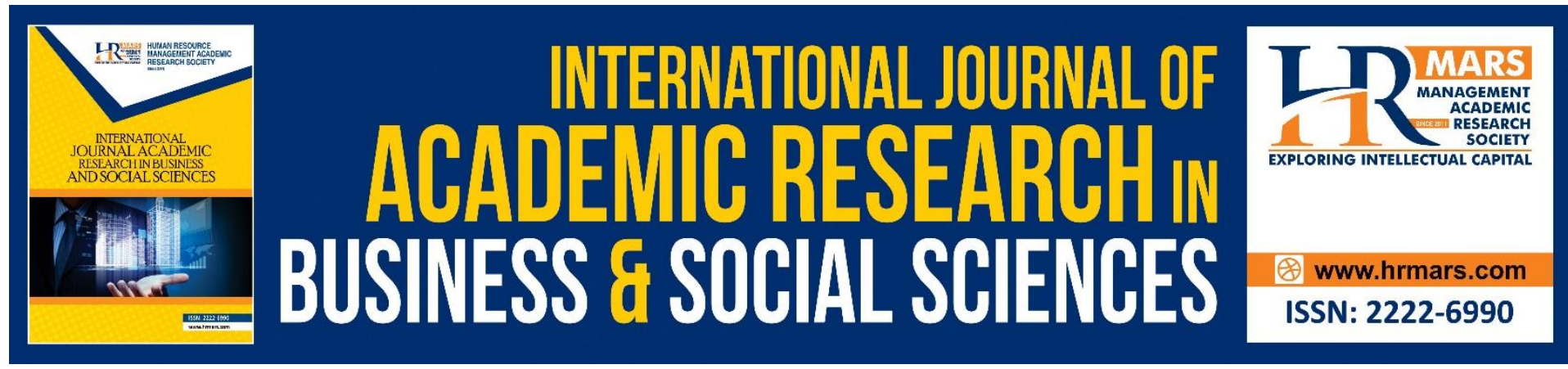

\title{
Innovation Diffusion and Mobile Payment Adoption amongst Postgraduate Students of UiTM Shah Alam
}

\author{
Mohd Safwan Ramli, Hazlin Hasan, Zuria Akmal Saad, \\ Muhammed Soffiq Saripin and Asmahan Zakaria \\ Faculty of Business and Management, Universiti Teknologi MARA Cawangan Pahang, \\ Lintasan Semarak, 26400 Bandar Pusat Jengka, Pahang, Malaysia. \\ Corresponding Author: safwanramli@uitm.edu.my, hazlin@uitm.edu.my, \\ zuria@uitm.edu.my, soffiq@uitm.edu.my
}

\begin{abstract}
The advances of technology and introduction of new innovation has changed the world. In Malaysia, the migration from paper-based to electronic payments has long been supported by Bank Negara with the introduction of mobile payment in 2018. The acceptance towards cashless payment shows that Malaysians are keeping pace with the advancement of technologies but still hesitating as mobile payment services in Malaysia are not being widely exposed to the consumers. Therefore, the study was conducted to identify the determinants of innovation diffusion that lead to the mobile payment adoption as well as to determine the relationship between innovation diffusion and mobile payment adoption among the postgraduate students of Universiti Teknologi MARA (UiTM) Shah Alam. 180 respondents were selected among the postgraduate students from eight programs of DPPS UiTM Shah Alam using convenience sampling. Statistical Package for the Social Sciences (SPSS 26) Multiple Regression was used to analyse the data collected using online questionnaire to assess the strength of the relationship between an outcome. The findings indicated that all five determinants of innovation diffusion have relationships with mobile payment adoption with the highest being Perceived Usefulness and Perceived Compatibility. It was also found that the most significant impacting mobile payment adoption was Perceived Usefulness. By providing a system that supports user's work performance, productivity, and effectiveness, it is expected to increase the willingness of future users to use mobile payment.
\end{abstract}

Keywords: Innovation Diffusion, Mobile Payment

\section{Introduction}

The advances of technology and introduction of new innovation has changed the world. In this digital age, everything is computerized and digitalized, which promotes cashless environment (Oliveira et al., 2016). Pham and Ho (2015) stated that the consumers need not bring huge amount of cash to make payments where they can just perform transactions using mobile payment systems. Besides, the evolvement and advancement of technologies 
has led to the innovations in mobile services. In addition, mobile payment acts as one of the recent technological innovations and being looked as 'innovation' and 'innovative service' (Apanasevic, 2015). For example, consumers familiarized with the commerce first, then with the introduction of internet banking or mobile banking before the term of mobile payment came into their mind (Oliveira et al., 2016; Okereke and Hedderman, 2017).

In Malaysia the migration from paper-based payments (cash and cheque) to electronic payment has been long supported by Bank Negara Malaysia since early 2013. The first wave, BNM introduced electronic fund transfer, the next wave was a debit card and currently is mobile payment. The introduction of mobile payment in 2018 was in order to support the mobile users estimated at 42.8 million (75.9\% smartphone penetration). Among the mobile users, only 12 million users had a bank account and actively used internet banking. Meanwhile, there were 2 million of mobile users that did not have a bank account and the rest of 10 million were non-online banking users. Thus, this would be targeted as new entrances to adopt the mobile payment (Lee and Daniel, 2015).

\section{Problem Statement}

Nowadays, the world is moving toward Industrial 4.0 (I 4.0), which means that everything will be digitised, including the introduction of mobile payment. According to E-Marketer (2016), smartphone users will increase from 1.57 billion in 2014 to 2.87 billion in 2020. This is due to advancements in the functionality of smartphones. While mobile technologies have been widely adopted and are increasingly accepted by consumers, it is surprising that mobile payment services in Malaysia have not been widely exposed to consumers, leaving them unaware of the services. This is because mobile payment services are still relatively new in Malaysia, and it will take time for them to be fully accepted and utilised by consumers (Mun, Khalid and Nadarajah, 2017). In Malaysia, a 2016 Visa Consumer Payment Attitudes Study found that $70 \%$ of Malaysians were willing to adopt mobile payments (Lin, 2017). Additionally, it was reported that smartphone penetration is increasing in Malaysia, with $71 \%$ of the adult population owning at least one smartphone. This acceptance of cashless payment demonstrates that Malaysians are keeping up with technological advancements while also contributing to the country's goal of becoming a cashless society.

There are numerous reasons why consumers continue to resist mobile payment technology adoption. One of the issues is that there is still a lack of trust in electronic payments (Kothari, 2018). Consumers have a sense of insecurity when using the Internet to make mobile payments. According to ISACA's 2015 Mobile Payment Security Study, over 900 cybersecurity professionals believe that mobile payment threats are real and pose significant perceived security risks. Additionally, some mobile payment services do not provide sufficient added value to entice consumers to use mobile payment (Martin, 2016). As a result, consumers are disinclined to use mobile payment for payment transactions.

Additionally, even though mobile payment enables cashless transactions and other beneficial features, it cannot guarantee that the system will be adopted and used by everyone. For instance, the traditional barrier rendered an individual's existing values, prior experience, and social norms incompatible with the advancement of new technologies (Laukkanen, 2016). As a result, users have not fully embraced mobile payment technology. As a result, the researchers proposed conducting a study on mobile payment adoption and innovation diffusion among postgraduate students at Universiti Teknologi Malaysia Shah Alam. 


\section{Research Questions}

RQ1: Is there any relationship between Innovation Diffusion and Mobile Payment Adoption? RQ2: Is there any relationship between Perceived Usefulness and Mobile Payment Adoption? RQ3: Is there any relationship between Perceived Ease of Use and Mobile Payment Adoption? RQ4: Is there any relationship between Perceived Compatibility and Mobile Payment Adoption?

RQ5: Is there any relationship between Subjective Norms and Mobile Payment Adoption?

RQ6: Is there any relationship between Individual Mobility and Mobile Payment Adoption?

RQ7: Which is the highest determinant of Innovation Diffusion that results in Mobile Payment Adoption?

RQ8: Which is the most significant determinant of Innovation Diffusion in relation to the adoption of mobile payment among postgraduate students of UiTM Shah Alam?

RQ9: Is there a significant relationship between Innovation Diffusion and Mobile Payment Adoption among postgraduate students of UiTM Shah Alam?

\section{Literature Review}

Innovation Diffusion

The world is expanding at a rapid pace, owing to technological advancements and innovations. Additionally, over the last two decades, there have been numerous new technologies, innovations, and new business practises, most notably in financial information systems and technology (Liu et al., 2015). Additionally, a previous study reported an increase in the number of people who use mobile technologies. However, this is in contrast to Malaysia's sparse use of mobile payment services (Mun et al., 2017). Perhaps this is because there is a dearth of research on mobile payment and the public is unaware of this payment method (Pietro et al., 2015). As a result, previous research indicated that it was necessary to ascertain the primary factors that influence consumers' intention to use mobile payment services (Mun et al, 2017). Additionally, another previous study suggested that prior to implementing any new payment system, it was critical to consider the customer perspective rather than the manufacturer perspective. Additionally, one of the major determinants of consumer adoption of mobile payment systems is the transaction's effective cost (Bezhovski, 2016).

Perceived Usefulness. The term "usefulness" refers to the degree to which an individual believes his or her performance will improve as a result of utilising the system (David, 1989). Individuals will be more willing to accept the system if they perceive the technology to be useful, as opposed to those who do not see the utility of the technology. On the other hand, numerous studies have documented a positive and significant relationship between Perceived Usefulness and the intention to use and adopt new systems. For example, perceived usefulness is a critical factor in the adoption of mobile payment systems (LiebanaCabanillas et al., 2018). According to their findings, users perceived the future Short Message Service (SMS) mobile payment system to be more useful than the future Near Field Communication (NFC) mobile payment system. This demonstrates that Perceived Usefulness plays a critical role in determining the acceptance and adoption of new systems by users.

Perceived Ease of Use. Ease of Use refers to an individual's perception that using technology is effortless, either physically or mentally. Perceived Ease of Use can be defined in this study as the degree to which an individual believes that using mobile payment will be effortless. 
Additionally, a previous study reported that the primary determinants of individual acceptance or rejection of technologies were Perceived Usefulness and Perceived Ease of Use (David, 1989). Additionally, due to the lack of constraints associated with mobile payment, an individual may find the technology tedious and complex. For instance, the degree to which an individual believes that using mobile payment will be effortless due to the complexity of the features on mobile devices with a small display screen or the difficulty in entering information during use can be defined as the extent to which an individual believes that using mobile payment will be effortless.

Perceived Compatibility. Compatibility is viewed as a critical determinant of the innovation spread process, with individuals freely adopting new ideas, technologies, or even mobile payments if they have a high degree of compatibility (Hanafizadeh et al., 2014). Pham and Ho (2015), for example, stated that users are more likely to adopt Near Field Communication (NFC) mobile payment systems if they believe the new payment services are compatible with their daily lives. This was also supported by a previous study, which concluded that users' compatibility with new technologies could assist them in reducing potential uncertainty associated with their use. NFC is a type of mobile payment that necessitates proximity (Su et al., 2017). For example, with the introduction of NFC technology, users can now pay for transportation fares or even in-store purchases using their cell phones (Pham and Ho, 2015).

Subjective Norm. The $21^{\text {st }}$ century industry is defined by the evolution of technology, which began with the introduction of mobile payment shortly after the Internet's inception. However, mobile payment services are still relatively new to Malaysian users, and it is necessary to ascertain the factors influencing users' intentions to use and adopt these payment services (Mun et al., 2017). Additionally, a previous study on the acceptance of new mobile payment systems discovered that users may be uncertain due to perceived risks associated with using the new system (Liebana-Cabanillas et al., 2014). As a result, they viewed consultation with others' perspectives and experiences as critical determinants of their decision to adopt mobile payment. For instance, users can solicit opinions or suggestions from others via a variety of social media platforms. Additionally, subjective norms can be thought of as perceived social pressure exerted by certain referents such as relatives, friends, and other individuals with whom individuals have a close relationship. Perceived social pressure then has the potential to activate an individual's behaviour.

Individual Mobility. Individual mobility enabled the easy, rapid, and effective sharing of information, as well as the conduct of transactions regardless of the location of individuals or businesses (Cavus and Chingoka, 2015). Mobile payment services enable users to conduct transactions at any time and from any location, providing convenience and value to users while also facilitating service delivery (Gao and Waechter, 2015). Mobility is cited as a key feature that distinguishes traditional payment systems from the new mobile payment system. Additionally, mobility is defined as an individual's capacity to make payments regardless of time or location. For example, mobile payment systems enable consumers to complete all transactions even when they are physically unable to do so, such as paying bills while travelling. Due to the fact that people cannot be in multiple locations at the same time, the mobile payment system is ideal for performing any transactional processes (Dastan and Gurler, 2016). Additionally, the payment system's mobility is perceived to enable it to reach a greater number of consumers, as consumers are free to conduct transactions regardless of 
time or location constraints. Additionally, mobility enabled users to conduct transactions remotely via a mobile phone or other mobile device in the case of mobile banking adoption (Parijat, 2016). As a result, users can access any banking-related activity with ease.

\section{Adoption of Mobile Payment}

Mobile technologies have been widely adopted and are gaining consumer acceptance (Mun et al., 2017). Surprisingly, mobile payment services in Malaysia have not been widely publicised, leaving consumers unfamiliar with the services. This is because mobile payment services are still relatively new in Malaysia, and it will take time for them to be fully accepted and utilised by consumers. Additionally, the evolution of payment methods began with barter, progressed to currency, credit, and, most recently, the introduction of mobile payment, which focuses on electronic and mobile commerce. Since January 2014, China's mobile internet user base has surpassed 500 million, according to the China Internet Network Information Center (CNNIC). This is in contrast to Malaysia, where Statista (2018) reported that the country's mobile phone internet users totaled only 19.81 million in 2018, compared to China, where the number has already surpassed 500 million since 2014. With the advancement of technology in China, service providers are releasing a variety of mobile services, including mobile instant messaging, mobile search, mobile games, and mobile payment. Additionally, mobile payment appears to be receiving significant attention as a fundamental application of the mobile business. Users in China, for example, have been exposed to mobile payment via Alipay, the country's largest online payment service provider. Additionally, users in China can make payments via mobile devices via the WeChat payment system, which was introduced by Tencent, the country's largest instant messaging company. Given Alipay's entry into the Malaysian market, Neoh, the founder of FavePay, stated that Malaysia is prepared to go cashless (Neoh, 2018).

\section{Diffusion of Innovation on Adoption of Mobile Payment}

The originator of the diffusion of innovation theory introduced it as a predictor of new technology adoption based on the relative advantage, complexity, compatibility, trialability, and observability of the innovation (Rogers, 2003). However, relative advantage and complexity were omitted from this study because they are comparable to TAM's Perceived Utility and Perceived Ease of Use. However, in a study of mobile NFC (Near Field Communication) payments in Korea and Thailand, perceived relative advantage was retained because it was found to influence and be positively associated with mobile payment adoption. Mobile banking's advantages of immediate, convenience, and affordability will continue to entice users to use mobile payment in the future. This is consistent with previous research indicating that perceived compatibility, subjective norms, individual mobility, and personal inventiveness all influence the decision to adopt new technologies (LiebanaCabanillas et al, 2018). Another previous study discovered a significant correlation between two TAM model constructs and the intention to use mobile payment services in Malaysia (Mun et al, 2017).

\section{Conceptual Framework}

Conceptual framework for the relationship between Innovation Diffusion and Mobile Payment Adoption is given in fig. 1. 


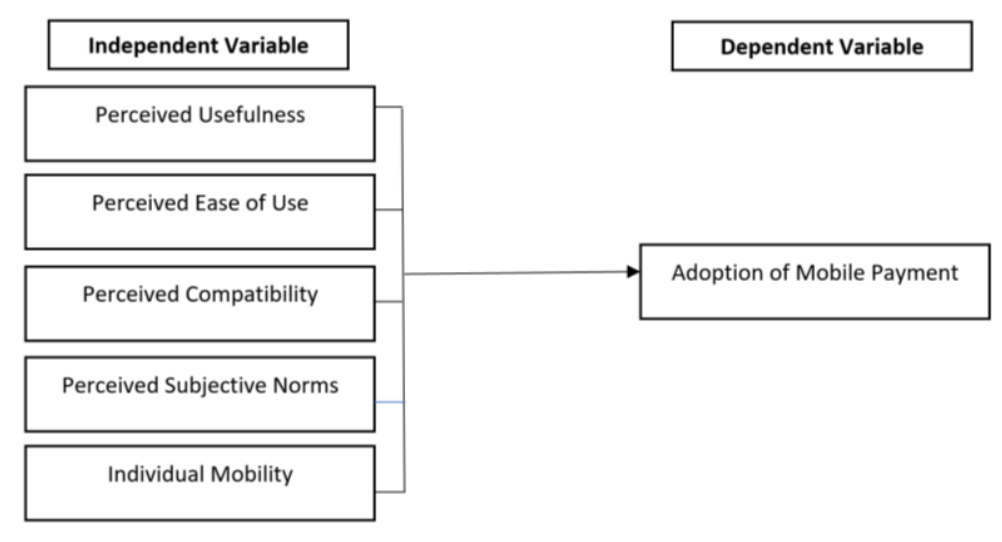

Fig. 1. Conceptual framework for the relationship between Innovation Diffusion and Mobile Payment Adoption.

\section{Hypotheses}

$\mathrm{H}_{1}$ There is positive relationship between Perceived Usefulness and Mobile Payment Adoption. $\mathrm{H}_{2}$ There is positive relationship between Perceived Ease of Use and Mobile Payment Adoption. $\mathrm{H} 3$ There is positive relationship between Perceived Compatibility and Mobile Payment Adoption. $\mathrm{H} 4$ There is positive relationship between Subjective Norms and Mobile PaymentAdoption.

$\mathrm{H} 5$ There is positive relationship between Individual Mobility and Mobile Payment Adoption.

\section{Methodology}

The data was collected from the postgraduate students of Department of Postgraduate and Professional Studies (DPPS) in UiTM Shah Alam taking the Master of Applied Entrepreneurship, Master in Customer Service Management, Master in Office Systems Management, Masters of Business Economics, Master of Human Resource Management, Master of Science (Business Management), Doctor of Philosophy (Office Systems Management) and Doctor of Philosophy (Business management) programmes. 180 students were selected using the convenient sampling to answer the questionnaires which was distributed online as shown in table 1 . Convenience sampling was used in this study as the population was unknown to the researchers and the method itself was economical, prompt and uncomplicated (San Martinz and Herrero, 2012). The instrument for Innovation Diffusion consisted of 37-items while Mobile Payment Adoption was measured using 8-items and the questions was adopted and adapted from previous study (Hair, 2006). A five-points Likert scale was used with the values range from $1=$ strongly disagree to $5=$ strongly agree.

Table 1. Response Rate.

\begin{tabular}{llll}
\hline University & $\begin{array}{l}\text { Questionnaires } \\
\text { Distributed }\end{array}$ & Questionnaires Returned & Return Rate (\%) \\
\hline DPPS & 180 & 180 & 100 \\
\hline
\end{tabular}

\section{Result and Discussion}

\section{Reliability Analysis}

For the Innovation Diffusion, all determinants were reported to have Cronbach's Alphas of > 0.9, which indicated a high level of consistency (Sekaran, 2006; Hair, Black, Babin and 
Anderson, 2010). The determinants were Perceived Usefulness, Perceived Ease of Use, Perceived Compatibility, Subjective Norm and Individual Mobility. The researchers decided to use the instrument as it is a well-established set of questionnaires commonly used in various studies on Innovation Diffusion. In fact, this instrument was found to be a reliable instrument in Malaysia's settings, whereby the Cronbach's Alpha readings were all greater than 0.7 (Hair et al, 2010). Next, the instrument on Mobile Payment Adoption was reported to have Cronbach's Alphas of $>0.8$, which is highly reliable (Sekaran, 2006; Hair et al, 2010). The researchers decided to use the instrument as it is a well-established set of questionnaires commonly used in various studies.

\section{Pearson-Correlation and Multiple Regression Analysis}

Table 2 shows the findings on the correlation between five determinants of Innovation Diffusion which are Perceived Usefulness, Perceived Ease of Use, Perceived Compatibility, Subjective Norm and Individual Mobility towards Mobile Payment Adoption among the students of DPPS UiTM Shah Alam. The result pointed out that all variables have significant positive relationships with Mobile Payment Adoption ( $r=.743, r=.706, r=.734, r=.619, r=$ $.436, p<.01$ ). Furthermore, the result also confirmed that there were significant positive relationships between Perceived Usefulness and Perceived Compatibility on Mobile Payment Adoption, which indicated that the greater the level of Perceived Usefulness and Perceived Compatibility among the students would result in a higher Mobile Payment Adoption. Therefore, research question one was answered and hypotheses $\mathrm{H}_{1}, \mathrm{H} 2, \mathrm{H} 3, \mathrm{H} 4$ and $\mathrm{H} 5$ were supported.

Table 2. Correlation between respondents' Innovation Diffusion and Mobile Payment Adoption.

\begin{tabular}{|c|c|c|c|c|c|c|}
\hline & 1 & 2 & 3 & 4 & 5 & 6 \\
\hline Perceived Usefulness & 1 & $.736^{* *}$ & $.777^{* *}$ & $.640^{* *}$ & $.545^{* *}$ & $.743^{* *}$ \\
\hline Perceived Ease of Use & $.736^{* *}$ & 1 & $.892^{* *}$ & $.733^{* *}$ & $.621^{* *}$ & $.706^{* *}$ \\
\hline $\begin{array}{l}\text { Perceived } \\
\text { Compatibility }\end{array}$ & $.777^{*}$ & $.892^{* *}$ & 1 & $.735^{* *}$ & $.642^{* *}$ & $.734^{* *}$ \\
\hline Subjective $\quad$ Norm & $.640^{* *}$ & $.733^{* *}$ & $.735^{* *}$ & 1 & $.667^{* *} 1$ & $.619^{* *}$ \\
\hline Individual Mobility & $.545^{* *}$ & $.621^{* *}$ & $.642^{* *}$ & $.667^{* *}$ & & $.436^{* *}$ \\
\hline $\begin{array}{l}\text { Mobile } \\
\text { Adoption }\end{array}$ & $.743^{* *}$ & $.706^{* *}$ & $.734^{* *}$ & $.619^{* *}$ & $.436^{* *}$ & 1 \\
\hline
\end{tabular}

\footnotetext{
**Correlation is significant at the 0.01 level

(1-tailed)

*Correlation is significant at the 0.05 level

(2-tailed)
} 


\section{Multiple Regression Analysis}

Findings from the regression analysis between Innovation Diffusion variables which were Perceived Usefulness, Perceived Ease of Use, Perceived Compatibility, Subjective Norm and Individual Mobility and Mobile Payment Adoption were tabulated in table 3.

Table 3. Multiple Regression Analysis.

\begin{tabular}{llll}
\hline Independent variables & & Standardized Coefficients Beta & Sig. \\
\hline Perceived Usefulness & .412 & 5.560 & .000 \\
Perceived Ease of Use & .145 & 1.376 & .171 \\
Perceived Compatibility & .271 & 2.396 & .018 \\
Subjective Norm & .154 & 2.049 & .042 \\
Individual Mobility & -.155 & -2.412 & .017 \\
\hline R Square & .635 & & \\
F & 60.893 & & \\
Sig. F Value & .000 & & \\
Durbin Watson & 1.973 & & \\
\hline
\end{tabular}

It was found that $R^{2}$ was .635 , in which all of the independent variables such as Perceived Usefulness, Perceived Ease of Use, Perceived Compatibility, Subjective Norm and Individual Mobility explained $63.5 \%$ of the variance ( $R$ square) for Mobile Payment Adoption, with significant of $F$ value of .000 . Plus, the Durbin Watson value was 1.973 , which values approaching 1.5-2.0 indicating positive autocorrelation, in line with one of the assumptions for bivariate and multivariate correlation analysis. The analysis revealed that Perceived Usefulness was the most influential component of Innovation Diffusion on the mobile payment adoption $(B=.412, p<.000)$. Consecutively, four variables of Innovation Diffusion which were Perceived Ease of Use, Perceived Compatibility, Subjective Norm, and Individual Mobility were not influential toward mobile payment adoption. Therefore, it can be concluded that Perceived Usefulness significantly contributed to predicting the mobile payment adoption.

Descriptive Statistics

The descriptive amongst postgraduate students revealed two most important predictors of innovation diffusion in order to enhance employee mobile payment adoption which are the constructs of perceived usefulness and subjective norms. Perhaps, these two constructs are absent in the postgraduate students, thus allowing postgraduate students to be less effective in mobile payment adoptions. For the purpose of this study, descriptive statistics were computed for both independent and dependent variables in order to compare the level of innovation diffusion amongst postgraduate students. The interpretation of the scores were based on the Best Principle (Thaoprom, 2004). Scores were divided by three ranges which are high, average and low with the computation like this: 5-1/3=1.33.

Thus, the results are:

- $\quad$ Scores between 1-2.33= Low Scores

- $\quad$ Scores between 2.34-3.67 = Moderate Scores

- $\quad$ Scores between 3.68-5.00 = High Scores 
The assessment on the level of innovation diffusion for amongst postgraduate students had a slightly higher the sub-variables perceived usefulness, perceived ease of use, perceived compatibility, subjective norms and individual mobility were found to be high amongst postgraduate at UiTM Shah Alam.

Table 6: Level of Innovation Diffusions

\begin{tabular}{lllll}
\hline Variable & N & Mean & Std Deviation & Level \\
\hline Perceived Usefulness & 180 & 4.3922 & .61836 & High \\
Perceived Ease of Use & 180 & 3.7179 & .74699 & High \\
Perceived Compatibility & & 4.0367 & .67229 & High \\
& 180 & & & \\
Subjective Norms & 180 & 4.4450 & .44793 & High \\
Individual Mobility & 180 & 3.6170 & .79754 & High \\
\hline & & & & \\
Innovation Diffusion & 180 & 3.9849 & .48164 & High
\end{tabular}

The findings based on the postgraduate students have been supported by various mobile payment adoptions studies. According to Koenig-Lewis, Marquet, Palmer, \& Zhao, (2015) reported that the way mobile adoption and their ability to successfully lead others can be influenced by Innovation diffusion. This was also supported by Oliveira, Thomas, Baptista, \& Campos, (2016). Mobile payment: Understanding the determinants of customer adoption and intention to recommend the technology. Computers in human behaviour, 61, 404414.who stated that innovation diffusion played a major role in developing an mobile payment adoption. Regardless of the innovation diffusion dimensions, the need for innovation diffusion in increasing mobile payment adoption are vital.

\section{Discussion}

The study's recommendations may be useful as guidance for mobile service providers in ensuring that users are not hesitant to adopt mobile payment systems. This research will also help them develop competitive strategies that will allow them to effectively target potential mobile payment users. To ensure that users perceive the technology as useful, the payment system's feature should allow users to pay more quickly. In a previous study, it was discovered that Perceived Usefulness was the strongest predictor of mobile payment acceptance. As a result, it is suggested that mobile service providers conduct adequate promotional campaigns emphasising the benefits of using this technology (Pham and Ho, 2015). Campaigns should emphasise the benefits of using mobile payment systems, such as faster shopping, more secure transactions, and improved performance. It is hoped that all of these advantages will persuade users to use mobile payment services.

As an added bonus, when the steps for using a payment system are simple for users to follow, those users will perceive the technology as being Ease of Use, and as a result, they will not encounter difficulties in adopting the technology (Liebana-Cabanillas et al., 2018). It is recommended that mobile service providers create user-friendly instructions or provide a step-by-step video to users in order for them to have a clearer picture when using the system. Apart from that, Perceived Compatibility is a critical factor in determining whether or not mobile payment will be adopted. When users see the benefits of using mobile payment to perform certain activities, they may perceive mobile payment to be more compatible with those activities (Oliveira et al., 2016). Because the mobile phone has 
become an indispensable tool for almost everyone, it is recommended that mobile service providers implement features on all mobile devices that support the mobile payment system. When considering the Near Field Communication (NFC) system, which is becoming increasingly popular as a widespread and common technology in today's world, mobile service providers should make certain that this system is compatible with the users' mobile devices, which will allow them to conduct transactions directly. Both the mobile device and the payment terminal must have an NFC chip, and the payment terminal must be capable of communicating with the NFC chip. Apple Pay, Samsung Pay, and Google Pay are just a few examples of applications that make use of the NFC system technology.

In addition, Subjective Norm is a significant factor in determining whether or not mobile payment will be adopted by consumers. Previous research has demonstrated that Subjective Norms may have a direct causal effect on a person's behavioural intentions as a result of the individual's perceived social pressure that stimulates their intentions on whether or not to use new systems (Liebana-Cabanillas et al., 2018). As a result, it is recommended that the mobile service provider make every effort to ensure that their customers are satisfied when they use the system. It is possible for their customers' word of mouth to be a powerful tool in persuading their friends and relatives to use a mobile payment system.

Individual Mobility, last but not least, is perceived to have an impact on the adoption of mobile payment systems. According to the findings of a previous study, mobility is perceived to have a positive impact on the adoption of mobile payment systems (Neoh, 2018). As a result of the dynamic nature of their lifestyles, it has been noted that modern users have less and less free time, which explains why mobility is considered to be one of the most important advantages of mobile payment. Accordingly, it is recommended that the service provider provide features that users can use regardless of their location or time, and that they ensure the appropriate technological infrastructure, which provides universally available, instantaneous, and dependable connections and services, thus providing users with a true anytime, anywhere connectivity experience.

\section{Conclusion}

The purpose of this study, which was carried out among postgraduate students at the University of Technology, Shah Alam, was to determine the relationships between Innovation Diffusion and Mobile Payment Adoption. It was discovered through statistical analyses that five determinants of innovation diffusion (perceived usefulness, perceived ease of use, perceived compatibility, subjective norm, and individual mobility) had statistically significant and positive relationships with the acceptance of mobile payment services. It was also discovered that only perceived usefulness had a positive impact on mobile payment adoption, with the other determinants having no significant impact on mobile payment adoption. This demonstrates that the findings of this study are consistent with previous research, which has found that perceived usefulness has a significant impact on the adoption of mobile payments. However, studies that examine the innovation diffusion dimension as a predictor of mobile payment adoption are still lacking in the field of mobile payment adoption. As a result, this study adds to the existing body of knowledge about mobile payment adoption literature by providing additional insights into the use of mobile payment. The adoption of mobile payments among students is influenced by many factors, one of which is innovation diffusion, which can be summarised as follows: It is anticipated that by providing a system that supports the user's work performance, 
productivity, and effectiveness, the willingness of future users to use mobile payment will increase.

\section{Theoretical Contributions}

Since this study found innovation influences mobile payment adoption. Mobile payment adoption is an important element that was used to influence the mobile payment adoption. This used TAM and Roger diffusion innovation model, which was the original concept of innovation diffusion. The results of the study present a gap in the literature review of Mobile payment adoption (Cavus and Chingoka, 2015). This study by (Dastan and Gurler, 2016) discover that innovation diffusion influences mobile payment adoption. In contract to previous research employed innovation diffusion to determine the mobile payment adoption effect in the context of postgraduate students in UiTM Shah Alam.

\section{References}

Apanasevic, T. (2015). Challenges related to the introduction of innovative services in the market: Mobile payment services in the Swedish retail industry Stokholm: KTH Royal Institute of Technology.

Bezhovski, Z. (2016). The future of the mobile payment as electronic payment system European Journal of Business and Management, 8(8), pp 127-132.

Cavus, N., and Chingoka, D. N. C. (2015). Information technology in the banking sector: Review of mobile banking. Global Journal Information Technology, 5(2), pp 62-70.

Dastan, I., and Gurler, C. (2016). Factors affecting the adoption of mobile payment systems: An empirical analysis. Emerging Markets Journal, 6(1), pp 17-24.

Davis, F. D. (1989). Perceived usefulness, perceived ease of use and user acceptance of information technology. MIS Quarterly, Vol 13, Electronic Commerce Research and Applications, 5(3), pp 246-257.

eMarketer. (2016). Number of smartphone users worldwide from 2014 to 2020. Retrieved from https://www.emarketer.com/Article/Slowing-Growth-Ahead-WorldwideInternet-Audience. Accessed 16 March 2020.

Gao, L., and Waechter, K. A. (2015). Examining the role of initial trust in user adoption of mobile payment services: An empirical investigation Information System Front, pp 124.

Hair, J. F., Black, W., Babin, B., and Anderson, R. (2010). Multivariate Data Analysis: Global Edition, $7^{\text {th }}$ Edition Pearson Education.

Hanafizadeh, P., Behboudi, M., Koshksaray, A. A., and Tabar, M. J. S. (2014). Mobile banking adoption by Iranian bank clients. Telematics Inform, 31(1), pp 62-78.

Kim, H. E., Chan, H. C., and Gupta, S. (2007). Value-based adoption of mobile internet: an empirical investigation. Decision support system, 43(1), pp 111-126.

Kothari, S. (2018). 5 reasons why consumers still don't use digital payments. Retrieved from https://economictimes.indiatimes.com/wealth/spend/5-reasons-why-consumersstill-dont- use-digital-payments/articleshow/64699938.cms?from=mdr. Accessed 20 March 2020.

Koenig-Lewis, N., Marquet, M., Palmer, A., \& Zhao, A. L. (2015). Enjoyment and social influence: predicting mobile payment adoption. The Service Industries Journal, 35(10), 537-554.

Laukkanen, T. (2016). Econpapers: consumer adoption versus rejection decisions in seemingly similar service innovations: The case of the internet and mobile banking. 
Journal of Business Research, 69(7), pp 2432-2439.

Lee Z.W. and Daniel K.P.T. (2018). Transforming mobile phones into e-wallets in Malaysia Bank Negara Malaysia, pp 36-43.

Liebana-Cabanillas, L. F., Fernandez, S., and Leiva, M. F. (2014). Antecedents of the adoption of the new mobile payment systems: The moderating effect of age. Computer Human Behaviour, 35, pp 464-478.

Liebana-Cabanillas, L. F., Marinkovic, V., Luna, I. R., and Kalinic, Z. (2018) Predicting the determinants of mobile payment acceptance: A hybrid SEM-neural network approach Technological Forecasting \& Social Change, 129, pp 117-130.

Lin, W. E. (2017). 70\% of Malaysians ready to adopt mobile payments, says Visa The Edge Markets. Retrieved from https://www.theedgemarkets.com/article/70-malaysiansready-adopt- mobile-payments-says-visa. Accessed 2 April 2020

Liu, J., Kauffman, R. J., and Ma, D. (2015). Competition, cooperation and regulation: Understanding the evolution of the mobile payment's technology ecosystem. Electronic Commerce Research and Applications, 14, pp 372-391.

Martin, A. J. (2016). 7 reasons mobile payments still aren't mainstream Retrieved from https://www.cio.com/article/308045/7-reasons-mobile-payment-still-arentmainstream.html. Accessed 5 April 2020

Mun, Y. P., Khalid, H., and Nadarajah, D. (2017). Millennials' perception on mobile payment services in Malaysia Procedia Computer Science, 124, pp 397-404.

Neoh, J. (2018) Fave: Malaysia closer to cashless society with more mobile payment options. Retrieved from https://www.malaymail.com. Accessed 5 May 2020.

Okereke, D., and Hedderman, M. (2017). Factors driving mobile payment adoption: benefits challenges \& opportunities.

Oliveira, T., Thomas, M., Baptista, G., and Campos, F. (2016). Mobile payment: Understanding the determinants of customer adoption and intention to recommend the technology. Computers in Human Behavior, 61, pp 404-414.

Parijat, U. S. J. (2016) Analyzing user perspective on the factors affecting use intention of mobile based transfer payment. Internet Research, 26(1), pp 38-56.

Pham, T. T., \& Ho, J. C. (2015). The effects of product-related, personal-related factors and attractiveness of alternatives on consumer adoption of NFC-based mobile payments Technology in Society, 43, pp 159-172.

Pietro, L. D., Mugion, R. G., Mattia, G., Renzi, M. F., and Toni, M. (2015). The integrated model on mobile payment acceptance (IMMPA): An empirical application to public transport Transp. Res. C, 56, pp 463-479.

Rogers, E. M. (2003). Diffusion of Innovations, 5th ed. Free Press New York.

San Martinz, H., and Herrero, A. (2012). Influence of user' psychological factor on the online purchase retention in rural tourism: integrating innovativeness to the U-TAUT Framework. Tour. Manag., 33(2), pp 341-350.

Sekaran, U. (2006). Research methods for business: A skill building approach (4th ed.) New York: John Wiley \& Sons.

Statista. (2018). Mobile phone internet users in Malaysia 2015-2022 Retrieved from https://www.statista.com. Accessed 8 May 2020.

Su, P., Wang, L., and Yan, J. (2017). How users' internet experience affects the adoption of mobile payment: a mediation model. Technology Analytical Strategy Management, pp $1-12$. 